\title{
Patient-reported outcome measures for clinical decision-making in outpatient follow-up: validity and reliability of a renal disease questionnaire
}

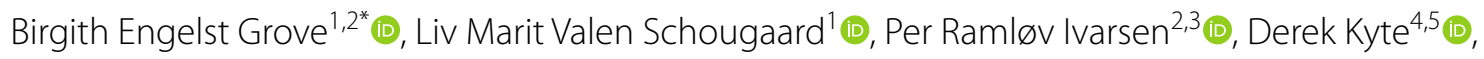
Niels Henrik Hjollund ${ }^{6,7}$ and Annette de Thurah ${ }^{2,8}$ (C)

\begin{abstract}
Background: Patient-reported outcome measures are increasingly used by clinicians to support communication in telephone- or face-to-face consultations with patients. A renal disease questionnaire has been developed, but not sufficiently evaluated through clinimetrics in clinical setting. Hence, we aimed to evaluate the content validity, construct validity and the test-retest reliability of a renal disease questionnaire to be used for clinical decision-making.

Methods: A content, construct validity and test-retest reliability study was conducted in 3 nephrology outpatient clinics in Central Denmark Region, Denmark. Content validity (face validity, comprehensibility and relevance) was assessed among 8 patients and 6 clinicians. Reliability was assessed by asking outpatients with chronic kidney disease to complete the questionnaire twice. Reliability was assessed by kappa statistics and agreement by percentage. Construct validity was determined using 4 a priori defined hypotheses and comparing 2 known groups.

Results: Five new domains emerged, 6 items were rephrased and 3 items were removed following the content validity test. A total of 160 patients completed the questionnaire with median 8 days (IQR 2 days) between assessments. The test-retest reliability parameters of the single items in the questionnaire were substantial to almost perfect as all the observed weighted kappa values ranged from 0.61 to $0.91,95 \% \mathrm{Cl}(0.34$ to 0.95$)$. In total, $61 \%$ of the single items showed almost perfect agreement. In total, 3 of the 4 hypotheses were accepted and $44 \%$ of the items showed satisfying known-group discriminative validity.

Conclusion: A renal disease questionnaire used for clinical decision-making in outpatient follow-up showed acceptable content validity and substantial to almost perfect reliability. Sufficient construct validity was not established. Incorporating the questionnaire into routine clinical practice may improve the evaluation of disease burden in patients with chronic kidney disease.

Plain English summary: We ask patients with chronic kidney disease (CKD) in Central Region Denmark to complete a questionnaire before each outpatient visit. The answers they provide are used to support communication with their health care provider. A questionnaire requires testing to ensure it can accurately capture important information about patient's symptoms and quality of life. When questionnaires are used to support communication between patients and health care professionals, they need to have good measurement properties. This means they need to
\end{abstract}

\footnotetext{
*Correspondence: bigcri@rm.dk

${ }^{1}$ AmbuFlex, Center for Patient-Reported Outcomes, Regional Hospital

West Jutland, Herning, Denmark

Full list of author information is available at the end of the article
} 
be: (1) trustworthy, (2) relevant to a patient's health condition, (3) consistent and produce stable results every time. We explored the measurement properties of a questionnaire designed to be used in the face-to face outpatient visits for patients with CKD. We found that the questionnaire captured consistent and stable results. Using this questionnaire may help health care professionals to assess the patients' burden of symptoms with a more patient-centered approach. Potentially, the use of the questionnaire will increase the patients' ability to cope with their symptoms and strengthen patients' involvement in the clinical decisions concerning their treatment.

Keywords: Renal insufficiency, Ambulatory care, Patient reported outcome measures, Reproducibility of results

\section{Background}

Chronic kidney disease (CKD) significantly impacts general health and well-being [1]. Patients with CKD are commonly frail, due to substantial comorbidity and significant symptom burden [1,2]. The severity of CKD is categorized: CKD stages 1-3a are anticipated to be largely asymptomatic. However, in CKD stages $3 \mathrm{~b}$, 4 and 5, the symptom burden increases [3]. Common symptoms include fatigue, loss of appetite, pruritus, restless legs and cognitive dysfunction $[2,4,5]$.

In Denmark, outpatient follow-up in patients with CKD stage $3 \mathrm{~b}-5$ has traditionally been based on regular face-to-face consultations. However, since 2012, there has been a growing interest in measuring and using patient reported outcomes (PROs) for remote data capture [6-8]. PRO measures capture information about a patient's health status directly from the patient [9]. PRO measures provide important information regarding the patients' perspective on the degree and impact of disease symptoms [10]. Recent studies support the use of PRO measures in clinical practice with improved shared decision-making $[11,12]$, patient-clinician communication [13-16], promoting accuracy of symptom assessment [17], and patient self-management [1820]. Remote $P R O$ data may also help in managing use of healthcare resources [21-23]. Several PRO instruments used to monitor health status among patients with CKD have been evaluated [24] and previous studies have explored the implementation of PRO instruments in a pre-dialysis population [25-27]. The Kidney Disease Quality of Life-36 (KDQOL-36) questionnaire has been recommended in pre-dialysis patients, even though it was developed for patients in dialysis care $[24,28]$. The KDQOL-36 has been validated in a Danish setting, but lacks evidence to support important properties on internal consistency, reliability and construct validity. Moreover, it is only tested in patients on dialysis in a Danish setting. [29]. Another study developed a clinical questionnaire [27], however this study was small and had several limitations such as low evidence for reliability and validity. Thus, there is a need for development of a reliable disease-specific instrument accurately measuring the most common symptoms, such as fatique, pruitus, nausea and loss of appetite, experienced by patients with CKD [1,2].

In 2012, a renal disease questionnaire (RDQ) was developed and used to monitor general health status and to facilitate communication between patients and health professionals in the 3 nephrology outpatient clinics in Central Denmark Region with 858,083 inhabitants corresponding to $15 \%$ of the Danish population [30]. The RDQ was developed in close cooperation between clinicians and patients, and was tested for face-validity [31]. However, validity and reliability are essential psychometric properties for any measure [32,33], and the ability of a PRO instrument to improve decision-making in clinical practice relies on the ability of the instrument to accurately capture the burden of disease or treatment [32]. The validity and reliability of the final questionnaire has not yet been evaluated, which is pivotal in the development of the instrument [32]. Therefore, we needed to demonstrate if the RDQ shows sufficient validity and is reliable so it may be deployed in clinical practice. This psychometric testing represents a first step toward supporting the questionnaire's use in clinical practice [34].

\section{Aims}

We aimed to evaluate the face and content validity and test-retest reliability of the single items included in the questionnaire used as support in clinical decision-making in nephrology outpatient follow-up. Furthermore, we aimed to evaluate the construct validity of burden of symptoms by establishing known group validity.

\section{Methods}

\section{Renal disease questionnaire (RDQ) Historical development}

The development of the questionnaire was iterative and based on consensus decision-making and face-to-face meetings with patients and clinicians. The process initiated in 2012 and was divided into two phases: (1) defining aim, content and construction of the questionnaire; and (2) pilot-testing. The renal disease questionnaire (RDQ) was implemented into clinical practice and was adapted based on experiences from clinical practice once yearly until 2017. 


\section{Content}

The content was based on existing validated PRO instruments or items. Additionally, ad hoc items were developed if existing instruments or items were not available. This process was supported by nephrology specialists, a systematic literature search, and patient interviews. The prototype RDQ included information specific to aspects of daily life with CKD. The instrument consisted of 3 items regarding general health and fatigue from the Short Form-36 (SF-36) [35, 36]. SF-36 is a generic questionnaire with 8 subscales measuring physical and mental health [36], and the psychometric properties of the Danish SF-36 have been well documented [35, 37]. Seven items regarding lack of appetite, pruritus, dizziness, nausea, dyspnoea, reduced concentration and memory from the Kidney Disease Quality of Life Short Form (KDQOLSF) [28] were included, some of which have been modified after the pilot test. The KDQOL-SF questionnaire combines the generic SF-36 scale and disease-specific components for assessing health-related quality of life in CKD patients [28]. Additionally, 5 items including frequent nocturnal urination, daily activities, worries about the future, oedema, and sleeping disorder were selected from the European Organization for Research and Treatment (EORTC) QLQ questionnaires [38] designed to measure quality of life in patients with cancer. However, these items are consistent with symptoms reported among patients with CKD [2, 5]. Finally, ad hoc items concerning e.g. drug adherence, blood pressure and weight were added.

\section{Clinical use of the questionnaire}

The questionnaire is used to support clinical decisionmaking and communication in nephrology outpatient clinics. A clinical expert group has assigned each item response into 3 colours: red, yellow or green. Red indicates that the patient is experiencing a particular problem within this domain; Yellow indicates that the patient is experiencing slight to moderate problems; and green indicates that the patient is not experiencing any problems within the domain. A graphical PRO overview of the patient response is embedded in the electronic health record [31].

\section{Study population Face and content validity}

In total, 8 patients participated in cognitive interviews and 6 clinicians participated in a focus group interview in order to evaluate face and content validity. Patients attending the nephrology outpatient clinics at Aarhus University Hospital and Central Regional Hospital, Viborg, were invited. Patients were selected purposively

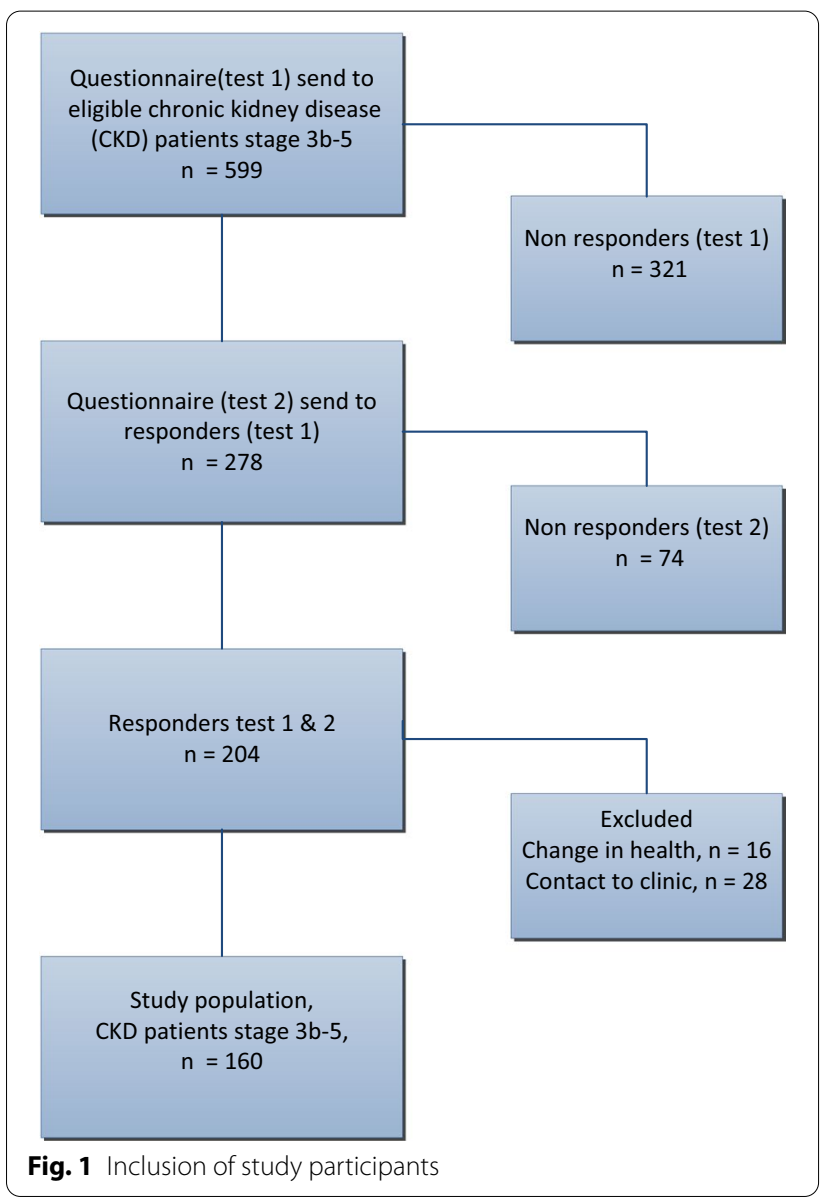

in order to maximise the variation of informants in terms of CKD duration, age, gender and experience of using the RDQ in the clinical encounter. Clinicians attending the focus group interview were selected based on their role in the organisation. Hence, participants from the management team, physicians and nurses were represented.

\section{Construct validity and test-retest reliability}

The target population was patients who had answered the questionnaire prior to a visit to the outpatient clinic within the previous 5 years. Inclusion criteria were age $\geq 18, C K D$ stage $3 \mathrm{~b}-5$ [3] in pre-dialysis care, as these patients often experience the symptoms asked in the questionnaire [2, 39-41]. All patients were contacted by "e-boks", a secure electronic mailbox for all citizens in Denmark. The reliability analysis consisted of 160 responders of test 1 and test 2 and the construct validity analysis was based on the 278 responders of test 1. Figure 1 shows the inclusion of study participants. 


\section{Procedure and analyses}

\section{Methods to evaluate content and face validity}

Content validity includes face validity and reflects whether the items in a questionnaire represent the concept of interest [42]. The purpose of cognitive interviewing was to assess the patients' and clinicians' comprehension of the separate items and the complete PRO instrument against the intended meaning. Comprehensibility and usability, relevance and deficits of the questionnaire were assessed in one-to-one semistructured interviews with 8 patients and 6 clinicians participating in a focus group. Table 1 shows the characteristics of the participants in the content and face validity analyses.

Sampling followed the criteria of 'sampling to redundancy'; that is to say interviewing people until no new information emerges [43]. Methodologically, the practice of cognitive interviewing patients as well as clinicians comprised 2 general techniques; "thinking aloud" and "verbal probing" while completing the questionnaires and also commenting on the layout and implication to clinical practice, following an interview protocol $[44,45]$. All interviews were recorded and transcribed verbatim according to the interview guides shown in an Additional file 1. The researcher BEG, who is also a skilled interviewer and experienced nurse within the field of clinical nephrology, carried out the interviews and transcriptions.

\section{Construct validity}

Construct validity is defined by the COnsensus-based Standards for the selection of health status Measurement INstruments (COSMIN) panel as the degree to which the

Table 1 Characteristic of the participants in the face and content validity study

N (\%)

\begin{tabular}{ll}
\hline Patients, semi-structured interviews $(\mathrm{N}=8)$ & \\
Gender, men & $6(80)$ \\
Age, median [min;max] & $72[59 ; 86]$ \\
Aarhus University Hospital & $5(62)$ \\
Central Regional Hospital, Viborg & $3(38)$ \\
Years followed-up in the outpatient clinic, median [min;max] & $4[1 ; 8]$ \\
Clinicians, focus group (N=6) & \\
Gender, men & $1(16)$ \\
Age, median [min;max] & $51[44 ; 61]$ \\
Nurse & $3(50)$ \\
Physician & $2(33)$ \\
Team manager & $1(17)$ \\
Years of experience, median [min;max] & $14[6 ; 27]$ \\
Aarhus University Hospital & $6(100)$ \\
\hline
\end{tabular}

scores of a measurement instrument are consistent with hypotheses, e.g. with regard to internal relationships or differences between relevant groups [46]. According to the COSMIN criteria, the construct validity of an instrument is sufficient when $75 \%$ of the predefined hypotheses are confirmed in a sample of at least 50 patients [42]. We used the Wilson and Cleary conceptual model of health status as a theoretical framework to explain how constructs may be related and how symptom status affects the functional status and the patients' general health perception. Each symptom represents a construct, which is a measure of a symptom [47]. In the present study, the construct of interest was the symptoms perceived by patients with CKD and the impairment of the physical function. Construct validity was assessed by comparing associations between selected single PRO measures and similar or divergent health-related outcomes.

Based on previous findings [7, 48, 49], we hypothesised that:

The correlation between nocturnal awakening and low daily activity would be moderate to good $(\mathrm{r}=>0.50)$

The correlation between high self-rated health and low renal function would be negligible $(r=0.10-$ 0.30 )

The correlation between lack of appetite and feeling aversion to food would be moderate to good $(\mathrm{r}=>0.50)$

High Quality of life (EQ-5D) would correlate moderately to good $(r=>0.50)$ with high daily activities

We used Spearman rank correlation coefficients due to the ordinal nature of the items. Correlations were considered as follows: 0.10 to $0.30=$ little or no relationship, 0.30 to $0.50=$ fair relationship, 0.50 to $0.70=$ moderate to good relationship, and $>0.70=$ good to excellent relationship [50]. The shape and direction of the relationship between the selected items will be computed in Stata graph bars and reported. Finally, we assessed the capacity of each item in the questionnaire to discriminate between 3 subgroups of patients; patients in CKD stage $3 b(n=141)$, CKD stage $4(n=69)$ and CKD stage $5(n=23)$ [51]. Due to the low number of participants in stage 5 , we combined participants in stage 4 and 5 in the analyses. We described the proportion and percentage of participants in each category and used the Mann-Whitney test for unequal distributions in these groups [46].

\section{Reliability}

Reproducibility was assessed by examining the degree of agreement between scores on the measure at first assessment and when reassessed [46]. The final version of the 
RDQ (Additional file 2) following the validity analyses formed the basis for conducting the test-retest analysis. Data collection took place from May to August 2019. Participants completed the questionnaire at 2 time points. By e-mail, patients were informed of the study details, and asked to complete the questionnaire (named 'test 1 '). Non-responders received a reminder after 2 days. Subsequently, the same questionnaire (named 'test 2') was sent to the responders of 'test 1 '. No reminders were sent. Time between 'test 1' and 'test 2' was 7 days. The testretest study was performed in patients with stable disease activity, i.e. patients who in the test 2 questionnaire answered "somewhat the same" to the question: "Compared to a week ago, how is your health all in all now?" and "no" to the question: "During the past week have you been in contact with the outpatient clinic?". Test-retest reliability and agreement were assessed within the item categories. In nominal and ordinal data, respectively unweighted and weighted kappa statistics with squared weights were used to assess reliability [32]. The $95 \%$ confidence intervals (CI) for weighted kappa values were measured using non-parametric bootstrap methods with 1000 replications [52]. The kappa agreement was interpreted as follows: $<0.2$ (slight), 0.21-0.4 (fair), 0.41-0.60 (moderate), 0.61-0.80 (substantial), and 0.81-1.0 (almost perfect) [53]. Perfect agreement (identical responses at the two time points) and proportion of agreement was used to assess agreement measures [32]. A sensitivity analysis with patients who had been in contact with the outpatient clinic or who had reported a change in health condition was performed.

\section{Other analyses}

Descriptive statistics was presented as means and standard deviations (SDs), medians and interquartile ranges (IQR) or numbers (\%) according to the distribution. Differences between responders and non-responders were evaluated by $\mathrm{X}^{2}$ test for categorical variables and the Mann-Whitney test for continuous variables with nonnormal distributions. Lack of response was assessed for all items and was considered unacceptable if data was missing in more than $5 \%$ of an item category. Floor and ceiling effects were assessed and considered present if a high proportion $(>15 \%)$ of the respondents had a score at the lower or upper end of the scale [34]. We used the Charlson Comorbidity Index to estimate the burden of comorbidity $[54,55]$. Information on the patients' diagnosis and renal function was obtained from the Hospital Business Intelligence Register in Central Denmark Region [56].

A formal sample size calculation was not carried out in the present study due to the pragmatic design, where we approached all patients who had answered the questionnaire prior to a visit to the outpatient clinic within the previous 5 years. The overall recommendation regarding sample size in reliability studies is to include at least 50 patients [34]. A 5\% significance level using twosided tests was chosen, and STATA 16 was used for all analyses. This study followed the requirements from the COSMIN Risk of bias checklists for content validity, reliability and hypotheses testing for construct validity [57]. See checklist (Additional File 3).

\section{Results}

\section{Content and face validity}

The full results of the cognitive interviewing are shown in Additional File 4: Table S1. Three items in the questionnaire were removed, 6 questions were rephrased and 5 new items emerged. Clinicians reflected on the length of the questionnaire and relevance for the patients and underlined the importance of a short and concise questionnaire. Patients highlighted the importance of knowing the purpose of the questionnaire. The majority of patients found the content of the questionnaire relevant, and no critical comprehension difficulties were identified. The time used to fill in the questionnaire did not raise any criticism, average time for completion was $8 \mathrm{~min}(\mathrm{~min}$ 4; $\max 13)$. Upon revision, the final version of the RDQ (Additional file 2), provided the basis for psychometric analyses.

\section{Test-retest reliability and agreement of single items}

In total, 599 questionnaires were sent out to patients at time point 1 , and 278 questionnaires were sent out at time point 2. Questionnaire returns were $278(46 \%)$ at time point 1 and 204 (73\%) at time point 2, giving a total response rate of $34 \%$. After exclusion of patients reporting a change in health $(\mathrm{n}=16)$ and those who had been in contact with the outpatient clinic $(n=28)$, the study population consisted of 160 patients with CKD stage 3b-5 (Fig. 1). Patient characteristics are shown in Table 2.

Non-responders were more likely to be younger $(p=0.04)$ and female $(p<0.001)$ (Table 2). The median age was 69 (IQR 18.5) years. In total, 67\% reported suffering from other conditions, which affected their health besides CKD, such as arthritis, diabetes, pain, heart failure and cancer. The mean burden from comorbidity from the CCI was 1.31 (SD 1.5, range $0-8$ ).

The median response time from test 1 to test 2 was 8 days (IQR 2, range 5-28 days). The test-retest reliability parameters of the single items in the RDQ were substantial to almost perfect as all the observed weighted kappa values were above $0.61,95 \%$ CI (0.34 to 0.95 ). Perfect agreement ranged from 55 to $96 \%$ in each single item. Totally, $61 \%$ of all items showed almost perfect agreement, as shown in Additional file 5: Table S2. 
Table 2 Patient characteristics measured at time for test 1 in responders and non-responders in test 2 among outpatients with chronic kidney disease $(n=555)$

\begin{tabular}{|c|c|c|c|}
\hline & $\begin{array}{l}\text { Responders } \\
(n=160) \\
n(\%)\end{array}$ & $\begin{array}{l}\text { Non- } \\
\text { responders } \\
(n=395) \\
n(\%)\end{array}$ & $p$ value \\
\hline Gender, men & $115(71)$ & $225(57)$ & $<0.001$ \\
\hline Age, year median [IQR] & $69[18.5]$ & $56[30]$ & $0.04^{b}$ \\
\hline eGFR, median [IQR] & $28.2[10]$ & $33,4[10]$ & $0.78^{b}$ \\
\hline $\mathrm{CCl}$, mean (SD) & $1.31(1.5)$ & $1,28(1.31)$ & 0.82 \\
\hline Low 0 & 49(30) & $169(42)$ & \\
\hline Medium 1-2 & $88(55)$ & $175(44)$ & \\
\hline High $>2$ & $23(15)$ & $51(14)$ & \\
\hline \multicolumn{4}{|l|}{ Quality of life (EQ-5D) ${ }^{\mathrm{a}}$} \\
\hline Median, [IQR] & $0.80[30]$ & $0.80[20]$ & $0.97^{b}$ \\
\hline \multicolumn{4}{|l|}{ General healtha } \\
\hline Excellent & $16(10)$ & $5(7)$ & $0.76^{b}$ \\
\hline Very good & $37(23)$ & $22(30)$ & \\
\hline Good & $68(42)$ & $30(40)$ & \\
\hline Fair & $36(23)$ & $15(20)$ & \\
\hline Poor & $3(2)$ & $2(3)$ & \\
\hline
\end{tabular}

Patients reporting change in health and patients who have been in contact with the clinic are excluded

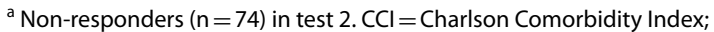
eGFR = estimated glomerular filtrations rate (renal function); EQ-5D = European Quality of life 5-Dimensions; IQR $=$ Inter Quartile Range; $p$-value $=$ Chi-squared or ${ }^{\mathrm{b}}$ Mann-Whitney; SD $=$ Standard Deviation

The sensitivity analysis including patients $(\mathrm{n}=204)$ who had contact with the outpatient clinic or who reported a change in health condition showed slightly reduced to perfect agreement, ranging from 52 to $92 \%$ and kappa values between $0.56-0.87,95 \%$ CI ( 0.37 to 0.92$)$, as shown in Additional file 6: Table S3. Missing responses were less than $3 \%$ in all items. For the majority of items, a skewed distribution was observed with high proportions of more than $15 \%$ at the upper or lower end of the scale, as shown in Additional file 5: Table S2.

\section{Construct validity}

Data supported the hypothesis in 3 of the 4 a priori constructed hypotheses. The results of hypotheses testing are shown in Table 3.

The distribution of self-reported characteristics to show independence between 2 known groups determining the discriminative validity is presented in the Additional file 7: Table S4. In total 10 of the 23 items (44\%) showed satisfying known-group validation in the RDQ.

\section{Discussion}

This is the first study investigating some of the psychometric properties of a disease-specific renal disease questionnaire (RDQ) used to support clinical decisionmaking in outpatient clinics. Face and content validity was found acceptable. In total, $44 \%$ of the items showed satisfying known-group discriminative validity and 3 of the 4 a priori hypotheses were accepted, demonstrating the initial step of establishing construct validity. The test-retest reliability kappa values of the single items in the questionnaire were substantial to almost perfect. In total, $61 \%$ of the single items showed almost perfect agreement.

\section{Content and face validity}

Patients emphasised the importance of knowing the purpose and clinical use of the questionnaire, which is crucial when implementing PRO measures in a clinical setting $[11,58]$. Similar findings have been reported in previous studies $[18,19,59,60]$. A recent systematic review found strong evidence supporting internal consistency and moderate evidence for construct validity for the KDQOL-36 in pre-dialysis patients [24], which formed the basis of the questionnaire in our study. The

Table 3 Construct validity: correlations ${ }^{\mathrm{a}}$ between selected PRO items among 278 outpatients with chronic kidney disease

\begin{tabular}{|c|c|c|c|c|c|c|}
\hline & Daily activities & Renal function & $\begin{array}{l}\text { Feeling } \\
\text { aversion to } \\
\text { food }\end{array}$ & Quality of life & Interpretation of correlation $(r)$ & Shape of relationship \\
\hline Nocturnal awakening & $\begin{array}{l}r=0.31 \\
p<0.0001\end{array}$ & & & & Hypothesis rejected & Negative linear \\
\hline Self-rated health & & $\begin{array}{l}r=0.19^{b} \\
p=0.004\end{array}$ & & & Hypothesis accepted & Negative linear \\
\hline Lack of appetite & & & $\begin{array}{l}r=0.77 \\
p<0.0001\end{array}$ & & Hypothesis accepted & Negative linear \\
\hline Daily activities & & & & $\begin{array}{l}r=0.58 \\
p<0.0001\end{array}$ & Hypothesis accepted & Negative linear \\
\hline
\end{tabular}

\footnotetext{
${ }^{\text {a }}$ Spearman correlation coefficients $(r)$ were calculated
}

${ }^{b} \mathrm{n}=233$ 
scale has been validated in a Danish setting, but has not yet reached recommended values [29]. The outpatient clinics needed an instrument to support clinical decision-making in terms of monitoring patients' health status; this means focusing on the most relevant questions from a clinician- and patient viewpoint [15]. Consistent with previous studies [11,61], our cognitive interviews supported that a questionnaire needs to address key issues and not be too comprehensive. The use of multiple 'single-domain' items within a measure allows the production of a short tool which, when compared to existing PROs, may be capable of measuring several patient-important domains using a less time-consuming format for patients and clinicians [62]. In contrast, singledomain items seem to lose sensitivity and are less reliable for tracking individual changes. However, the constructs measured in this questionnaire are unidimensional. Hence, a single item scale is considered appropriate [62]. Involving clinicians and patients in the evaluation of the questionnaire has potentially increased the feasibility and clinical relevance of the selected PRO measures.

\section{Construct validity}

Evaluation of construct validity includes the degree to which a measure correlates with other measures to which it is similar and diverges from measures that are dissimilar [46]. Since no comparative instrument was available, we formulated hypotheses based on prior findings in the literature. The selected PRO measures in the analyses of construct validity were assumed to be the most clinically relevant when monitoring the progression of CKD [1]. With a $75 \%$ rate of confirmed predefined hypotheses in this study of 278 patients with CKD, according the COSMIN quality criteria we reached sufficient construct validity [42]. However, as each item in the questionnaire represents a unique construct and therefore needs to be validated with its own hypothesis, we cannot claim to have reached sufficient construct validity. However, construct validity is a lengthy, ongoing process [63, 64], and this paper only demonstrates the initial step towards establishing construct validity. In total, 10 of the 23 items (44\%) in the RDQ showed satisfying known-group validation. Unfortunately, we needed to dichotomies data due to a low number of participants in the stage 5 group, and even though our findings are concurrent with the available literature $[2,7,65]$, this may potentially have blurred the results and have violated the overall findings. Apparently, the symptom score varies widely in patients with the comparable renal function. Several studies suggest that also social, psychological determinants and comorbid conditions play an important role in symptom development and burden [66-68]. Generally, QoL deterioate when renal funcion declines [69]. However, the relation between kidney disease specific symptoms and decline in renal function is not straightforward and litterature on this is scarce [70]. In the EQUAL group, they found a faster decline in renal function to be associated with higher symptom burden [66]. This may play a role when known group validation is conducted, whilst we cannot rule out some adaptation to long-term CKD. During the development process, redundant items should have been added to the questionnaire for validation purposes [63]. Unfortunately, this was not feasible in the design of this study. It should therefore be acknowledged that further research is required to provide additional evidence around construct validity. Hence, the four a priori chosen hypotheses from the selected items do not reflect on the construct validity of items not included in the hypotheses. However, this questionnaire serves as a clinimetric scale and does not necessarily need to satisfy the same requirements as a psychometric scale [63]. From a clinimetric perspective, a single-item measure could be useful as long as it discriminates between different groups of patients and reflects clinically relevant changes over time [71]. However, further psychometric analysis investigating the validity of single items will be needed before full construct validity is established.

\section{Reliability}

Overall, we found that test-retest reliability was considered substantial to almost perfect in all the included items in the RDQ, although some items showed only fair or moderate values at the lower end of the confidence intervals. However, kappa values are influenced by skewed distribution, number of classes, and systematic differences between the 2 measurements [72]. A skewed distribution leads to a lower extent of real agreement due to a higher fraction of chance agreement [72]. A skewed distribution in several items in the questionnaire was shown, probably due to a homogeneous population with stable disease activity and low symptom burden. This skewed distribution may have resulted in an underestimation of the kappa values [72]. A skewed distribution was observed with high proportions of more than $15 \%$ at the upper or lower end of the scale. Potentially, this could affect the reliability and the ability to distinguish patients with the lowest or highest score from each other [42]. From a clinician viewpoint this was considered acceptable as the items in the questionnaire represent alert symptoms, which indicate a potential hazard or condition requiring special attention. We found the lowest kappa values in the items concerning medication adherence $0.61(95 \% 0.34 ; 0.83)$ and vomiting showing kappa value at 0.69 (95\% 0.32; 0.90). However, the agreement in both items was high; $>98 \%$. The discrepancy between level of agreement and kappa may 
be caused by an unequal distribution and ceiling effect. This illustrates that kappa is affected by the prevalence of the measured event and distribution of item scores [72]. The outliers with low agreement represented items as fatique (55\% perfect agreement) and restless legs (62\% perfect agreement), which may be related to a certain day to day variation. Several potential threats related to the consistency of a PRO measurement may occur. A long interval increases the risk of a real change in patient status and a short interval increases the risk of recall bias [63]. The study population consisted of frail elderly people with a high level of comorbidity; this required that the interval between the assessments should be short due to variation in health. We had a time difference at 8 days (IQR 2 days) between test 1 and test 2, which is within the recommendation from the literature [32, 34]. A real change in the patient's health status between the 2 time points of measures might cause a potential error related to the consistency of a PRO measurement [63]. However, we excluded patients who reported a change in health status which strengthened our results. According to COSMIN framework, reliability needs to be tested in patients who are stable in the interim period on the construct to be measured [34]. Potentially, bias would occur if the patients failed to report a change in disease status due to recall problems. Another strength in the analyses was that the questionnaires were completed independent of a visit in the clinic and patients who had a visit at the outpatient clinic were excluded from the analyses (Fig. 1). If the disease status had changed upon treatment at the outpatient clinic, it might have induced risk of bias, as this represents responsiveness [34]. We performed sensitivity analysis including patients with a change in health condition or having contact with the outpatient clinic and found a tendency towards decreased reliability as expected.

A limitation in this study was the risk of selection bias. The response rate was only $34 \%$, which might have been caused by the pragmatic design. This only allowed us to approach a known group of patients without any a priori knowledge of their present renal function. Compared to non-responders, there were more elderly and more men among responders, whereas no significant difference in renal function was observed. A study population that does not represent the targeted population may challenge generalisation of the results. However, the differences between responders and non-responders are not likely to be clinically important. Importantly, the presence of some selection bias cannot be excluded, thus hampering the external validity of our findings. A use of reminders at test 2 could have increased the overall response rate. However, the participants did not receive reminders at test 2 to ensure an acceptable interval length between the 2 measurement points in a test-retest study [42]. The mode of administration only included web responders, which could potentially induce selection bias. However, in recent years, the use of web-based questionnaires has increased dramatically [73]. This could potentially underestimate the reliability parameters due to the homogeneous study population. Yet, the study population represents the target population and the real-life environment and a mere of $5 \%$ of the patients in the outpatient nephrology clinics responded to the questionnaire in a paper version.

Among the 3 main measurement properties domains in the COSMIN framework, we have investigated the validity and the reliability. The present study was not designed to evaluate responsiveness, which should be assessed in a longitudinal study. This would provide further evidence when using the RDQ to follow patients' health status over time.

Incorporating this questionnaire into clinical practice may allow measurement of outcomes that may be more relevant to approximately $600-800$ patients with CKD using this questionnaire. In the coming years we expect a more intense use of PRO measures in clinical practice [73], which highlights the importance of improving the quality of this PRO instrument.

\section{Conclusion}

This is the first study investigating some of the psychometric properties of a disease-specific renal disease questionnaire (RDQ) used to support clinical decision-making in outpatient clinics. Our study shows the importance of including end users when developing a questionnaire for clinical use. It is fundamental that the questions asked reflect the needs of the clinicians and patients. We have demonstrated the initial step in establishing construct validity. However, the construct validity and discriminative ability should be further investigated in future studies. Overall, RDQ showed substantial to almost perfect test-retest reliability. Further psycometric measurement properties and establishment of clinical responsiveness represents the final necessary steps before deploying this tool for use in clinical nephrology settings.

\footnotetext{
Abbreviations

CCl: Charlson Comorbidity Index; Cl: Confidence Intervals; CKD: Chronic kidney disease; COSMIN: COnsensus-based Standards for the selection of health status Measurement Instruments; EGFR: Estimated Glomerular Filtration Rate; EORTC: European Organization for Research and Treatment; EQ-5D: European Quality of life 5-Dimensions; IQR: Interquartile range; KDQOL-36: The Kidney Disease Quality of Life-36; PRO: Patient-reported outcome; RDQ: Renal Disease Questionnaire; SDs: Standard Deviations; SF-36: Short Form-36.
} 


\section{Supplementary Information}

The online version contains supplementary material available at https://doi. org/10.1186/s41687-021-00384-0.

Additional file 1. Interviewguide.

Additional file 2. Renal Disease Questionaire (RDQ).

Additional file 3. COSMIN Risk of BIAS checklist.

Additional file 4. S1. Results from the cognitive interviewing.

Additional file 5. Agreement and reliability between the items from test 1 to test 2 in original categories $(n=160)$.

Additional file 6 . Sensitivity analyses showing agreement and reliability between the items from test 1 to test 2 in original categories $(n=204)$.

Additional file 7. Known group (discriminiative validity) stratified into CKD stage $3 \mathrm{~b}$ and stage 4 and 5 at time for test 1 among 160 patients with chronic kidney disease.

\section{Acknowledgements}

Not applicable

\section{Authors' contributions}

$\mathrm{NHH}$ and BEG designed the study in collaboration with LMS, DK, PI and AdT. BEG and $\mathrm{NHH}$ participated in recruitment of participants. BEG performed the data collection, the statistical analyses and drafted the manuscript. LMS, AdT, $\mathrm{NHH}, \mathrm{DK}$ and $\mathrm{PI}$ contributed to interpretation of data and critical revisions of the manuscript. LMS, NHH, AdT, DK, PI and BEG read and approved the final manuscript and stand by the integrity of the entire work. All authors read and approved the final manuscript.

\section{Funding}

This study was supported by Trygfonden Grant Number: 124259

\section{Availability of data and materials}

A non-identifier version of the dataset used in this current study is available. Interested researchers may contact the corresponding author for further guidance.

\section{Declarations}

\section{Ethics approval and consent to participate}

The study was approved by the Danish Data Protection Agency (j.no: 1-1602-873-17). Patients consented to participate and allowed the researchers to obtain medical data from the Hospital Business Intelligence Register

\section{Consent for publication}

Not applicable.

\section{Competing interests}

DK reports grants from NIHR, grants from Innovate UK, grants from NIHR Birmingham Biomedical Research Centre, grants from NIHR SRMRC at the University of Birmingham and University Hospitals Birmingham NHS Foundation Trust, personal fees from Merck, personal fees from GSK, grants from Macmillan Cancer Support, grants from Kidney research UK, outside the submitted work.

\footnotetext{
Author details

${ }^{1}$ AmbuFlex, Center for Patient-Reported Outcomes, Regional Hospital West Jutland, Herning, Denmark. ${ }^{2}$ Department of Clinical Medicine, Aarhus University, Aarhus, Denmark. ${ }^{3}$ Department of Renal Medicine, Aarhus University Hospital, Aarhus N, Denmark. ${ }^{4}$ School of Allied Health and Community, University of Worcester, Worcester, UK. ${ }^{5}$ Aarhus University, Aarhus, Denmark. ${ }^{6}$ AmbuFlex/WestChronic, Occupational Medicine, University Research Clinic, Aarhus University, Herning, Denmark. ${ }^{7}$ Department of Clinical Epidemiology, Aarhus University Hospital, Aarhus N, Denmark. ${ }^{8}$ Department of Rheumatology, Aarhus University Hospital, Aarhus N, Denmark.
}

Received: 30 December 2020 Accepted: 5 October 2021

Published online: 16 October 2021

\section{References}

1. Levey AS, Coresh J (2012) Chronic kidney disease. Lancet 379(9811):165-180

2. Almutary $\mathrm{H}$, Bonner A, Douglas C (2013) Symptom burden in chronic kidney disease: a review of recent literature. J Ren Care 39(3):140-150

3. Levey AS, Coresh J, Bolton K, Culleton B, Harvey KS, Ikizler TA, Johnson CA, Kausz A, Kimmel PL, Kusek J, Levin A, Minaker KL, Nelson R, Rennke H, Steffes M, Witten B, Hogg RJ, Furth S, Lemley KV, Portman RJ, Schwartz G, Lau J, Balk E, Perrone RD, Karim T, Rayan L, Al-Massry I, Chew P, Astor BC, De Vine D, Eknoyan G, Levin N, Burrows-Hudson S, Keane W, Kliger A, Latos D, Mapes D, Oberley E, Willis K, Bailie G, Becker G, Burrowes J, Churchill D, Collins A, Couser W, DeZeeuw D, Garber A, Golper T, Gotch F, Gotto A, Greer JW, Grimm R Jr, Hannah RG, Acosta JH, Hogg R, Hunsicker L, Klag M, Klahr S, Lewis C, Lowrie E, Matas A, McCulloch S, Michael M, Nally JV, Newmann JM, Nissenson A, Norris K, Owen W Jr, Patel TG, Payne G, Rivera-Mizzoni RA, Smith D, Star R, Steinman T, Valderrabano F, Walls J, Wauters JP, Wenger N, Briggs J (2002) K/DOQI clinical practice guidelines for chronic kidney disease: evaluation, classification, and stratification. Am J Kidney Dis 39(2 SUPPL. 1):S-266

4. Campbell KH, Huang ES, Dale W, Parker MM, John PM, Young BA, Moffet $\mathrm{HH}$, Laiteerapong N, Karter AJ (2013) Association between estimated GFR, health-related quality of life, and depression among older adults with diabetes: the diabetes and aging study. Am J Kidney Dis 62(3):541-548

5. Heiwe S, Clyne N, Dahlgren MA (2003) Living with chronic renal failure: patients' experiences of their physical and functional capacity. Physiother Res Int 8(4):167-177

6. Trillingsgaard C, Nielsen BK, Hjøllund NH, Lomborg K (2016) Use of patient-reported outcomes in outpatient settings as a means of patient involvement and self-management support-a qualitative study of the patient perspective. Eur J Pers Centered Healthc 4(2):359

7. Grove BE, Schougaard LM, Hjollund NH, Ivarsen P (2018) Self-rated health, quality of life and appetite as predictors of initiation of dialysis and mortality in patients with chronic kidney disease stages 4-5: a prospective cohort study. BMC Res Notes 11(1):371

8. Schougaard LM, Larsen LP, Jessen A, Sidenius $P$, Dorflinger $L$, de Thurah $A$, Hjollund NH (2016) AmbuFlex: tele-patient-reported outcomes (telePRO) as the basis for follow-up in chronic and malignant diseases. Qual Life Res 25(3):525-534

9. Bottomley A, Jones D, Claassens L (2009) Patient-reported outcomes: Assessment and current perspectives of the guidelines of the Food and Drug Administration and the reflection paper of the European Medicines Agency. Eur J Cancer 45(3):347-353

10. Velikova G, Brown JM, Smith AB, Selby PJ (2002) Computer-based quality of life questionnaires may contribute to doctor-patient interactions in oncology. Br J Cancer 86(1):51-59

11. Porter I, Goncalves-Bradley D, Ricci-Cabello I, Gibbons C, Gangannagaripalli J, Fitzpatrick R, Black N, Greenhalgh J, Valderas JM (2016) Framework and guidance for implementing patient-reported outcomes in clinical practice: evidence, challenges and opportunities. J Comp Effect Res 5(5):507-519

12. Velikova G, Booth L, Smith AB, Brown PM, Lynch P, Brown JM, Selby PJ (2004) Measuring quality of life in routine oncology practice improves communication and patient well-being: a randomized controlled trial. J Clin Oncol 22(4):714-724

13. Ishaque S (2019) A systematic review of randomised controlled trials evaluating the use of patient-reported outcome measures (PROMs). Qual Life Res 28(3):567-592

14 Kotronoulas G (2014) What is the value of the routine use of patientreported outcome measures toward improvement of patient outcomes, processes of care, and health service outcomes in cancer care? J Clin Oncol 32(14):1480-1501

15. Boyce MB, Browne JP, Greenhalgh J (2014) The experiences of professionals with using information from patient-reported outcome measures to improve the quality of healthcare: a systematic review of qualitative research. BMJ Qual Saf 23(6):508-518 
16. Detmar SB, Muller MJ, Schornagel JH, Wever LD, Aaronson NK (2002) Health-related quality-of-life assessments and patient-physician communication: a randomized controlled trial. JAMA 288(23):3027-3034

17. Denis F, Basch E, Septans A-L, Bennouna J, Urban T, Dueck AC, Letellier C (2019) Two-year survival comparing web-based symptom monitoring vs routine surveillance following treatment for lung cancer. JAMA 321(3):306-307

18. Mejdahl CT, Schougaard LMV, Hjollund NH, Riiskjaer E, Thorne S, Lomborg K (2017) PRO-based follow-up as a means of self-management supportan interpretive description of the patient perspective. J Patient Rep Outcomes 2:38

19. Snyder CF, Aaronson NK, Choucair AK, Elliott TE, Greenhalgh J, Halyard MY, Hess R, Miller DM, Reeve BB, Santana M (2012) Implementing patientreported outcomes assessment in clinical practice: a review of the options and considerations. Qual Life Res 21(8):1305-1314

20. Basch E, Deal AM, Kris MG, Scher HI, Hudis CA, Sabbatini P, Rogak L, Bennett AV, Dueck AC, Atkinson TM, Chou JF, Dulko D, Sit L, Barz A, Novotny P, Fruscione M, Sloan JA, Schrag D (2016) Symptom monitoring with patient-reported outcomes during routine cancer treatment: a randomized controlled trial. J Clin Oncol 34(6):557-565

21. de Thurah A, Stengaard-Pedersen K, Axelsen M, Fredberg U, Schougaard LMV, Hjollund NHI, Pfeiffer-Jensen M, Laurberg TB, Tarp U, Lomborg K, Maribo T (2018) Tele-health followup strategy for tight control of disease activity in rheumatoid arthritis: results of a randomized controlled trial. Arthritis Care Res (Hoboken) 70(3):353-360

22. de Jong MJ, van der Meulen-de Jong AE, Romberg-Camps MJ, Becx MC, Maljaars JP, Cilissen M, van Bodegraven AA, Mahmmod N, Markus T, Hameeteman WM, Dijkstra G, Masclee AA, Boonen A, Winkens B, van Tubergen A, Jonkers DM, Pierik MJ (2017) Telemedicine for management of inflammatory bowel disease (mylBDcoach): a pragmatic, multicentre, randomised controlled trial. Lancet 390(10098):959-968

23. Riis CL, Jensen PT, Bechmann T, Möller S, Coulter A, Steffensen KD (2020) Satisfaction with care and adherence to treatment when using patient reported outcomes to individualize follow-up care for women with early breast cancer - a pilot randomized controlled trial. Acta Oncol 59(4):444-452

24. Aiyegbusi OL, Kyte D, Cockwell P, Marshall T, Gheorghe A, Keeley T, Slade A, Calvert M (2017) Measurement properties of patient-reported outcome measures (PROMs) used in adult patients with chronic kidney disease: a systematic review. PLoS ONE 12(6):e0179733

25. Chao S, Yen M, Lin TC, Sung JM, Wang MC, Hung SY (2016) Psychometric properties of the kidney disease quality of life-36 questionnaire (KDQOL36). West J Nurs Res 38(8):1067-1082

26. ElHafeez SA, Sallam SA, Gad ZM, Zoccali C, Torino C, Tripepi G, ElWakil HS, Awad NM (2012) Cultural adaptation and validation of the "Kidney Disease and Quality of Life-Short Form (KDQOL-SF ${ }^{T M}$ ) version 1.3" questionnaire in Egypt. BMC Nephrol 13(1):170

27. Agarwal R (2010) Developing a self-administered CKD symptom assessment instrument. Nephrol Dial Transplant 25(1):160-166

28. Hays RD, Kallich JD, Mapes DL, Coons SJ, Carter WB (1994) Development of the kidney disease quality of life (KDQOL) instrument. Qual Life Res 3(5):329-338

29. Molsted S, Heaf J, Prescott L, Eidemak I, Eidemak I (2005) Reliability testing of the Danish version of the Kidney Disease Quality of Life Short Form. Scand J Urol Nephrol 39(6):498-502

30. Denmark S (2020, June 2020) Population in Denmark Retrieved 24th July, 2020. https://www.dst.dk/en/Statistik/emner/befolkning-og-valg/befol kning-og-befolkningsfremskrivning/folketal

31. Hjollund NH, Larsen LP, Biering K, Johnsen SP, Riiskjaer E, Schougaard LM (2014) Use of patient-reported outcome (PRO) measures at group and patient levels: experiences from the generic integrated PRO system, WestChronic. Interact J Med Res 3(1):e5

32. Kottner J, Audige L, Brorson S, Donner A, Gajewski BJ, Hrobjartsson A, Roberts C, Shoukri M, Streiner DL (2011) Guidelines for reporting reliability and agreement studies (GRRAS) were proposed. J Clin Epidemiol 64(1):96-106

33. Aaronson N, Alonso J, Burnam A, Lohr KN, Patrick DL, Perrin E, Stein RE (2002) Assessing health status and quality-of-life instruments: attributes and review criteria. Qual Life Res 11(3):193-205

34. De Vet HCTL, Mokkink B, Knol DL (2016) Measurement in medicine-a practical guide. Cambridge University Press
35. Bjorner JB, Damsgaard MT, Watt T, Groenvold M (1998) Tests of data quality, scaling assumptions, and reliability of the Danish SF-36. J Clin Epidemiol 51(11):1001-1011

36. Bjorner JB, Thunedborg K, Kristensen TS, Modvig J, Bech P (1998) The Danish SF-36 Health Survey: translation and preliminary validity studies. J Clin Epidemiol 51(11):991-999

37. Bjorner JB, Kreiner S, Ware JE, Damsgaard MT, Bech P (1998) Differential item functioning in the Danish translation of the SF-36. J Clin Epidemiol 51(11):1189-1202

38. Aaronson NK, Ahmedzai S, Bergman B, Bullinger M, Cull A, Duez NJ, Filiberti A, Flechtner H, Fleishman SB, de Haes JC, de Haes JC et al (1993) The European Organization for Research and Treatment of Cancer QLQ-C30: a quality-of-life instrument for use in international clinical trials in oncology. J Natl Cancer Inst 85(5):365-376

39. Cohen SD, Patel SS, Khetpal P, Peterson RA, Kimmel PL (2007) Pain, sleep disturbance, and quality of life in patients with chronic kidney disease. Clin J Am Soc Nephrol 2(5):919-925

40. Finkelstein FO, Wuerth D, Finkelstein SH (2009) Health related quality of life and the CKD patient: challenges for the nephrology community. Kidney Int 76(9):946-952

41. Mucsi I, Kovacs AZ, Molnar MZ, Novak M (2008) Co-morbidity and quality of life in chronic kidney disease patients. J Nephrol 21(SUPPL. 13):S84-S91

42. Terwee $C B$, Bot SD, de Boer MR, van der Windt DA, Knol DL, Dekker J, Bouter LM, de Vet HC (2007) Quality criteria were proposed for measurement properties of health status questionnaires. J Clin Epidemiol 60(1):34-42

43. Willis GB (2004) Cognitive interviewing: a tool for improving questionnaire design. Sage Publications

44. Drennan J (2003) Cognitive interviewing: verbal data in the design and pretesting of questionnaires. J Adv Nurs 42(1):57-63

45 Priede C, Farrall S (2011) Comparing results from different styles of cognitive interviewing: 'verbal probing'vs. 'thinking aloud.' Int J Soc Res Methodol 14(4):271-287

46. Mokkink LB, Terwee CB, Patrick DL, Alonso J, Stratford PW, Knol DL, Bouter LM, de Vet HC (2010) The COSMIN study reached international consensus on taxonomy, terminology, and definitions of measurement properties for health-related patient-reported outcomes. J Clin Epidemiol 63(7):737-745

47 Wilson IB, Cleary PD (1995) Linking clinical variables with healthrelated quality of life. A conceptual model of patient outcomes. JAMA 273(1):59-65

48. Pruchno R, Wilson-Genderson M, Cartwright F (2009) Self-rated health and depressive symptoms in patients with end-stage renal disease and their spouses: a longitudinal dyadic analysis of late-life marriages. J Gerontol B Psychol Sci Soc Sci 64(2):212-221

49. Mapes DL, Lopes AA, Satayathum S, McCullough KP, Goodkin DA, Locatelli F, Fukuhara S, Young EW, Kurokawa K, Saito A, Bommer J, Wolfe RA, Held PJ, Port FK (2003) Health-related quality of life as a predictor of mortality and hospitalization: the dialysis outcomes and practice patterns study (DOPPS). Kidney Int 64(1):339-349

50. Hinkle DWWJS (2003) Applied statistics for the behavioral sciences, 5th edn. Houghton Mifflin

51. NKF (2013) KDIGO 2012 clinical practice guideline for the evaluation and management of chronic kidney disease, vol 2017. NKF

52. Reichenheim ME (2004) Confidence intervals for the kappa statistic. Stand Genomic Sci 4(4):421-428

53 Landis JR, Koch GG (1977) The measurement of observer agreement for categorical data. Biometrics 33:159-174

54. Charlson ME, Pompei P, Ales KA, MacKenzie CR (1987) A new method of classifying prognostic comorbidity in longitudinal studies: development and validation. J Chronic Dis 40(5):373-383

55. Quan H, Li B, Couris CM, Fushimi K, Graham P, Hider P, Januel J-M, Sundararajan $V$ (2011) Updating and validating the Charlson comorbidity index and score for risk adjustment in hospital discharge abstracts using data from 6 countries. Am J Epidemiol 173(6):676-682

56. Midt R. Business intelligence in central Denmark region.

57. Mokkink LB, Terwee CB, Patrick DL, Alonso J, Stratford PW, Knol DL, Bouter LM, de Vet HC (2010) The COSMIN checklist for assessing the methodological quality of studies on measurement properties of health status measurement instruments: an international Delphi study. Qual Life Res 19(4):539-549 
58. Valderas JM, Kotzeva A, Espallargues M, Guyatt G, Ferrans CE, Halyard MY, Revicki DA, Symonds T, Parada A, Alonso J (2008) The impact of measuring patient-reported outcomes in clinical practice: a systematic review of the literature. Qual Life Res 17(2):179-193

59. MejdahI CT, Schougaard LMV, Hjollund NH, Riiskjaer E, Lomborg K (2020) Patient-reported outcome measures in the interaction between patient and clinician - a multi-perspective qualitative study. J Patient Rep Outcomes $4(1): 3$

60. Primdahl J, Jensen DV, Meincke RH, Jensen KV, Ziegler C, Nielsen SW, Dalsgaard L, Kildemand M, Hetland ML, Esbensen BA (2019) Patients' views on routine collection of patient-reported outcomes in rheumatology outpatient care - a multicenter focus group study. Arthritis Care Res 72:1331-1338

61. Santana MJ, Haverman L, Absolom K, Takeuchi E, Feeny D, Grootenhuis M, Velikova G (2015) Training clinicians in how to use patient-reported outcome measures in routine clinical practice. Qual Life Res 24(7):1707-1718

62. Aaronson N, Choucair A, Elliott T, Greenhalgh J, Halyard M, Hess R, Miller D, Reeve B, Santana M, Snyder C (2011) User's guide to implementing patient-reported outcomes assessment in clinical practice. International Society for Quality Life Research

63. Fayers PM (2007) Quality of life: the assessment, analysis and interpretation of patient-reported outcomes, 2 nd edn. Wiley

64. Cappelleri JC (2014) Validity. In: Group TF (ed) Patient-reported outcomes. Measurement, implementation and interpretation. CRS Press, pp 31-51

65. Fukuhara S, Yamazaki S, Marumo F, Akiba T, Akizawa T, Fujimi S, Haruki S, Kawaguchi Y, Nihei H, Shoji T, Maeda T (2007) Health-related quality of life of predialysis patients with chronic renal failure. Nephron Clin Pract 105(1):c1-c8

66. Janmaat CJ, van Diepen M, Meuleman Y, Chesnaye NC, Drechsler C, Torino C, Wanner C, Postorino M, Szymczak M, Evans M, Caskey FJ, Jager KJ, Dekker FW, Investigators ES (2021) Kidney function and symptom development over time in elderly patients with advanced chronic kidney disease: results of the EQUAL cohort study. Nephrol Dial Transplant 36(5):862-870

67. Pagels AA, Soderquist BK, Heiwe S (2015) Differences in illness representations in patients with chronic kidney disease. J Ren Care 41(3):146-155

68. Subramanian L, Quinn M, Zhao J, Lachance L, Zee J, Tentori F (2017) Coping with kidney disease-qualitative findings from the Empowering Patients on Choices for Renal Replacement Therapy (EPOCH-RRT) study. BMC Nephrol 18(1):119

69. Pagels AA, Soderkvist BK, Medin C, Hylander B, Heiwe S (2012) Healthrelated quality of life in different stages of chronic kidney disease and at initiation of dialysis treatment. Health Qual Life Outcomes 10:71

70. Grams ME, Surapaneni A, Appel LJ, Lash JP, Hsu J, Diamantidis CJ, Rosas SE, Fink JC, Scialla JJ, Sondheimer J, Hsu CY, Cheung AK, Jaar BG, Navaneethan S, Cohen DL, Schrauben S, Xie D, Rao P, Feldman HI, investigators, C. S. (2020) Clinical events and patient-reported outcome measures during CKD progression: findings from the CRIC study. Nephrol Dial Transplant 36(9):1685-1693

71. Tomba E, Bech P (2012) Clinimetrics and clinical psychometrics: macroand micro-analysis. Psychother Psychosom 81(6):333-343

72. Viera AJ, Garrett JM (2005) Understanding interobserver agreement: the kappa statistic. Fam Med 37(5):360-363

73. Hjollund NHI (2019) Fifteen years' use of patient-reported outcome measures at the group and patient levels: trend analysis. J Med Internet Res 21(9):e15856

\section{Publisher's Note}

Springer Nature remains neutral with regard to jurisdictional claims in published maps and institutional affiliations.

\section{Submit your manuscript to a SpringerOpen ${ }^{\circ}$ journal and benefit from:}

- Convenient online submission

- Rigorous peer review

- Open access: articles freely available online

- High visibility within the field

- Retaining the copyright to your article

Submit your next manuscript at $\boldsymbol{\nabla}$ springeropen.com 